\title{
Correction to: Enhancing the performance of highly porous cellulose based nanocomposite membrane for possible application in forward osmosis desalination
}

\author{
Doaa Ahmed ${ }^{1,3} \cdot$ Heba Isawi $^{2}$ (D) Nagwa Badway ${ }^{3} \cdot$ Amina Elbayaa $^{3} \cdot$ Hosam Shawky $^{2}$
}

Published online: 22 September 2021

(c) Iran Polymer and Petrochemical Institute 2021

Correction to: Iranian Polymer Journal (2021) 30:423-444
https://doi.org/10.1007/s13726-021-00901-4

The article title originally read "Highly porous cellulosic nanocomposite membranes with enhanced performance for forward osmosis desalination". This has been corrected to "Enhancing the performance of highly porous cellulose based nanocomposite membrane for possible application in forward osmosis desalination" in this correction.

The original article can be found online at https://doi.org/10.1007/ s13726-021-00901-4.

Heba Isawi

hebaessawi@hotmail.com; heba_isawi@edrc.org.eg

1 Egyptian Desalination Research Center of Excellence (EDRC), Cairo, Egypt

2 Water Desalination Unit, Water Resources and Desert Soils Division, Hydrogeochemistry Department, Desert Research Center, Egyptian Desalination Research Center of Excellence (EDRC), Cairo, Egypt

3 Chemistry Department, Faculty of Science, Al-Azhar University, Nasr City, Cairo, Egypt 